\title{
Eficiência de Desinfestantes na Erradicação de Conídios de Mycosphaerella fijiensis Aderidos à Superfície de Bananas
}

\author{
Rogério E. Hanada $^{1}$, Luadir Gasparotto ${ }^{2}$ \& José Clério R. Pereira ${ }^{2}$ \\ ${ }^{1}$ Instituto Nacional de Pesquisas da Amazônia, INPA/CPPF, Cx. Postal 478, CEP 69011-970, Manaus, AM, e-mail: \\ rhanada@inpa.gov.br; ${ }^{2}$ Embrapa Amazônia Ocidental, Cx. Postal 319, CEP 69011-970, Manaus, AM
}

(Aceito para publicação em 08/09/2003)

Autor para correspondência: Rogério Eiji Hanada

HANADA, R.E., GASPAROTTO, L. \& PEREIRA, J.C.R. Eficiência de desinfestantes na erradicação de conídios de Mycosphaerella fijiensis aderidos à superfície de bananas. Fitopatologia Brasileira 29:094-096. 2004.

\section{RESUMO}

Os conídios de Mycosphaerella fijiensis agente causal da Sigatoka-negra da bananeira (Musa spp.) podem ser disseminados a longas distâncias, aderidos em diversos materiais, como tecidos e caixas. Neste contexto, o presente trabalho teve como objetivo selecionar desinfestantes eficientes para inibir a germinação de conídios do patógeno. Foram testados benomil, amônia quaternária, digluconato de chlorhexidina, formaldeído, óleo essencial de pimenta longa (OEPL), Ecolife-40, thiabendazole e hipoclorito de sódio, nas concentrações de 1, 5, 10, 25, 50 e $100 \mathrm{mg} / \mathrm{l}$. Os conídios do isolado LPM 472 foram produzidos em BDA. Para os testes transferiu-se $1 \mathrm{ml}$ de uma suspensão de $10^{5}$ conídios/ml de $M$. fijiensis para cada tubo de ensaio com $1 \mathrm{ml}$ de desinfestante na sua respectiva concentração. Após $30 \mathrm{~h}$ de incubação à temperatura ambiente, com o auxílio de um microscópio óptico, quantificou-se a viabilidade de 100 conídios, computando-se apenas os germinados. A amônia quaternária, o benomil, o Ecolife-40 e o thiabendazole a $100 \mathrm{mg} / \mathrm{l}$ inibiram totalmente a germinação. Esses mesmos produtos, aplicados em frutos colhidos em área com a doença, apresentaram a mesma eficiência, via imersão ou pulverização, nas concentrações de 100 e $200 \mathrm{mg} / \mathrm{l}$.

Palavras-chave adicionais: Musa spp., germinação conidial, sigatoka-negra.

\section{ABSTRACT}

Effects of disinfectants on the conidia germination of Mycosphaerella fijiensis the causal agent of black sigatoka in banana

The conidia of Mycosphaerella fijiensis the causal agent of black sigatoka in banana (Musa spp.) can be disseminated over long distances when attached to substrates like cloth and boxes. The aim of this work was to select of effective chemicals for inhibiting conidial germination. The chemicals tested were benomyl, ammonium quaternary, digluconate of chlorhexidine, formaldehyde, pepper essential oil, Ecolife-40, thiabendazol and sodium hypochloride, using the concentrations of $1,5,10,25,50$ and $100 \mathrm{mg} / 1$ for each one. For each concentration tested, $1 \mathrm{ml}$ of a conidial suspension $\left(10^{5}\right.$ conidia $\left./ \mathrm{ml}\right)$ of $M$. fijiensis isolate LPM472 grown on PDA for the tests, was transferred into test tubes filled with $1 \mathrm{ml}$ of the above chemicals. After $30 \mathrm{~h}$ of incubation at room temperature, 100 conidia were observed using light microscope and only germinated conidia were counted. The results show that germination was completely inhibited by ammonium quaternary, benomyl, Ecolife-40 and thiabendazol at $100 \mathrm{mg} / \mathrm{l}$. The same chemicals were also effective when fruits collected from an infected area, were treated by pulverization or immersion techniques (100 and $200 \mathrm{mg} / \mathrm{l})$.
Após a constatação do fungo Mycosphaerella fijiensis Morelet, agente causal da sigatoka-negra da bananeira (Musa spp.), no Município de Tabatinga, fronteira do Brasil com a Colômbia e o Peru, no estado do Amazonas (Pereira et al., 1998), o patógeno rapidamente se disseminou, em praticamente todos os municípios do Amazonas, e se encontra em todos os Estados da Região Norte do País, exceto Tocantins, e no Estado do Mato Grosso (Gasparotto et al., 2001).

Os esporos de M. fijiensis são disseminados principalmente pelo vento (Calvo \& Romero, 1998). As mudas de bananeiras doentes e as folhas infetadas com o patógeno colocadas entre os cachos, para evitar o ferimento dos frutos durante o transporte, também representam um meio eficiente e rápido para a disseminação do patógeno a longas distâncias (Pereira et al., 2000). Hanada et al. (2002b), estudando a sobre- vivência de conídios de $M$. fijiensis em diferentes materiais, constataram que os esporos sobrevivem por até 60 dias aderidos às folhas de bananeira e nos tecidos das roupas dos operários; até 30 dias em pedaços de madeira, plástico e papelão, usados na confecção de caixas para embalagens dos frutos; e na casca dos frutos, até o seu apodrecimento. Vale ressaltar que, na casca de frutos verdes da cultivar Prata Anã, colhidos em um bananal com alta severidade de sigatokanegra, foram encontrados até 11 mil conídios aderidos em cada fruto. Esses dados são indícios de que os próprios frutos, embalagens e veículos que transitam nos bananais afetados, além dos próprios operários, podem disseminar o patógeno a longas distâncias.

Além da proibição do transporte de mudas contaminadas e do uso de folhas para proteger os frutos de feri- 
Eficiência de desinfestantes na erradicação de conídios de Mycosphaerella...

mentos durante o transporte, no intuito de retardar a disseminação do patógeno, deve-se, ao mesmo tempo, utilizar produtos para desinfestação das embalagens, dos frutos e dos veículos que estão nas áreas contaminadas, antes de saírem em direção a áreas livres da doença.

Vários fungicidas já foram testados e selecionados por Gasparotto et al. (2002) para o controle da sigatoka-negra nas áreas de plantio. Entretanto, para o tratamento dos frutos, apenas o thiabendazole e o ecolife (Lichtemberg, 2001) são recomendados para o controle das podridões pós-colheita.

Este trabalho teve como objetivo selecionar produtos e doses eficientes na erradicação dos conídios de $M$. fijiensis aderidos aos frutos.

O trabalho foi conduzido no Laboratório de Fitopatologia da Embrapa Amazônia Ocidental e no Laboratório de Patologia de Madeira da Coordenação de Pesquisas de Produtos Florestais, Instituto Nacional de Pesquisas da Amazônia (INPA), em Manaus, AM.

Foram testados benomil, hipoclorito de sódio, amônia quaternária (Chemitec), digluconato de chlorhexidina, formaldeído, óleo essencial de pimenta longa (OEPL), thiabendazole e Ecolife - 40 nas concentrações de $1 \mathrm{mg} / 1,5 \mathrm{mg} / 1,10 \mathrm{mg} / 1,25$ $\mathrm{mg} / 1,50 \mathrm{mg} / 1$ e $100 \mathrm{mg} / \mathrm{l}$ do ingrediente ativo; a testemunha foi testada apenas com água destilada. O delineamento utilizado foi inteiramente casualizado, com quatro repetições por tratamento.

Os conídios do isolado LPM 472 de M. fijiensis foram produzidos conforme a metodologia descrita por Hanada et al. (2002b). Um mililitro de uma suspensão de $10^{5}$ conídios $/ \mathrm{ml}$ foi adicionado a um tubo de ensaio com $1 \mathrm{ml}$ do desinfestante na respectiva concentração e, posteriormente, mantido em temperatura de $25 \pm 2{ }^{\circ} \mathrm{C}$, por $30 \mathrm{~h}$. Após esse período, sob microscópio óptico, quantificaram-se 100 conídios, aleatoriamente, de cada parcela, computando-se apenas os esporos germinados. Consideraram-se germinados os esporos cujo tubo germinativo apresentava comprimento igual ou maior que $30 \mu \mathrm{m}$.

Em um segundo ensaio, os produtos benomil, thiabendazole, Ecolife-40 e amônia quaternária, nas concentrações de $50 \mathrm{mg} / 1,100 \mathrm{mg} / \mathrm{l}$ e $200 \mathrm{mg} / 1$, foram avaliados para erradicação de conídios de $M$. fijiensis aderidos aos frutos da cv. Prata Anã, obtidos de plantio com altos níveis de severidade no campo experimental da Embrapa Amazônia Ocidental, em Manaus/AM. O delineamento utilizado foi o inteiramente casualizado com quatro repetições por tratamento. A testemunha foi tratada com água destilada. Tanto à solução de cada desinfestante quanto à testemunha foi adicionado 0,5 $\mathrm{ml}$ do espalhante Agral/1. Foram selecionados, aleatoriamente, cinco cachos de banana verde. Desses cachos, foram retiradas 25 bananas, aleatoriamente, para cada repetição. Os produtos foram aplicados nos frutos por imersão na calda durante $5 \mathrm{~min}$ ou pulverização até o ponto de escorrimento. Em seguida, os frutos foram mantidos à temperatura ambiente por $24 \mathrm{~h}$. Após esse período, as bananas foram lavadas; os conídios, desalojados da superfície da casca com auxílio de um pincel e a suspensão, centrifugada por $2 \mathrm{~min}$ a $3.000 \mathrm{rpm}$. O sobrenadante foi descartado e acrescentados $2 \mathrm{ml}$ de água destilada ao precipitado, que foi ressuspendido e mantido em incubadora a $25 \pm 2{ }^{\circ} \mathrm{C}$ por $30 \mathrm{~h}$. Com auxílio de microscópio óptico, quantificaram-se 100 conídios, aleatoriamente, computando-se os germinados em cada tratamento.

Os produtos benomil, ecolife, thiabendazole e a amônia quaternária, na concentração de $100 \mathrm{mg} / 1$, apresentaram maior eficiência, inibindo totalmente a germinação dos conídios de $M$. fijiensis; enquanto que formaldeído, hipoclorito de sódio, óleo de pimenta longa e o digluconato de chlorhexidina inibiram parcialmente (Tabela 1).

O tratamento dos frutos por imersão ou pulverização com os produtos Ecolife-40, amônia quaternária, thiabendazole e benomil nas doses de $100 \mathrm{mg} / \mathrm{l} \mathrm{e} 200 \mathrm{mg} / \mathrm{l}$ inibiu totalmente a germinação dos conídios (Tabela 2), indicando que esses produtos, independentemente do método de aplicação, constituem bons erradicantes de conídios de $M$. fijiensis aderidos à casca dos frutos da bananeira.

Cordeiro \& Matos (2000) citam o thiabendazole e o benomil como os produtos mais utilizados, em âmbito mundial, no controle de doenças pós-colheita em banana. Para a inibição da germinação dos conídios do M. fijiensis, thiabendazole e benomil foram eficientes na concentração de $100 \mathrm{mg} / \mathrm{l}$, bem inferior àquelas recomendadas para tratamento

TABELA 1 - Percentagem de inibição da germinação de conídios de Mycosphaerella fijiensis submetidos a diferentes desinfestantes

\begin{tabular}{lcccccc}
\hline \hline \multirow{2}{*}{ Desinfestante } & \multicolumn{5}{c}{ Concentracão(mg/l) } \\
\cline { 2 - 7 } & $\mathbf{1}$ & $\mathbf{5}$ & $\mathbf{1 0}$ & $\mathbf{2 5}$ & $\mathbf{5 0}$ & $\mathbf{1 0 0}$ \\
\hline Benomil & 61,4 & 72,3 & 88,0 & 94,0 & 95,0 & 100,0 \\
Amônia quaternária & 71,0 & 77,1 & 90,4 & 91,6 & 96,0 & 100,0 \\
Digluconato de chlorhexidina & 27,7 & 56,6 & 62,7 & 63,9 & 72,3 & 88,0 \\
Formaldeído & 26,5 & 36,1 & 38,6 & 36,1 & 38,6 & 39,8 \\
Hipoclorito de sódio & 13,2 & 18,1 & 27,7 & 43,4 & 26,5 & 86,7 \\
Thiabendazole & 21,5 & 28,2 & 34,5 & 52,0 & 90,2 & 100,0 \\
Óleo de pimenta longa & 27,7 & 33,1 & 44,5 & 51,7 & 82,2 & 84,7 \\
Ecolife & 21,6 & 28,9 & 43,4 & 65,0 & 81,0 & 100,0 \\
Testemunha & & 5 & 0,0 & & \\
\hline
\end{tabular}

TABELA 2 - Percentagem de inibição da germinação de conídios de Mycosphaerella fijiensis aderidos em frutos de bananeira (Musa spp.) submetidos a diferentes produtos

\begin{tabular}{|c|c|c|c|c|c|c|}
\hline \multirow{2}{*}{ Desinfestante } & \multicolumn{2}{|c|}{$50 \mathrm{mg} / \mathrm{l}$} & \multicolumn{2}{|c|}{$100 \mathrm{mg} / \mathrm{l}$} & \multicolumn{2}{|c|}{$200 \mathrm{mg} / \mathrm{l}$} \\
\hline & $\mathrm{I}^{*}$ & $\mathbf{P} * *$ & I & $\mathbf{P}$ & $\mathbf{I}$ & $\mathbf{P}$ \\
\hline ernária & 68,3 & 73,2 & 100 & 100 & 100 & 100 \\
\hline Benomil & 71,1 & 74,9 & 100 & 100 & 100 & 100 \\
\hline Thiabendazole & 67,6 & 66,5 & 100 & 100 & 100 & 100 \\
\hline Ecolife & 59,5 & 64,7 & 100 & 100 & 100 & 100 \\
\hline Testemunha & 0,0 & 0,0 & 0,0 & 0,0 & 0,0 & 0,0 \\
\hline
\end{tabular}

$\mathrm{I}=$ Imersão e P $=$ Pulverização. 


\section{R.E. Hanada et al.}

de doenças pós-colheita, $200 \mathrm{mg} / \mathrm{l}$ e $400 \mathrm{mg} / 1$, respectivamente. Por outro lado, vale esclarecer que, dos produtos testados, apenas o thiabendazole está registrado no Brasil, para uso no tratamento pós-colheita em banana, conforme AgroFit (2002).

O Ecolife-40, quando testado em condições de campo por Gasparotto \& Pereira (2002), no controle da sigatokanegra, mostrou-se eficiente. Foi também eficiente no controle de podridões pós-colheita em banana (Lichtemberg, 2001), e na erradicação dos conídios do patógeno. Produto de origem natural, composto de bioflavonóides cítricos (Vit.P), fitoalexinas cítricas e ácido ascórbico (Vitamina C), o Ecolife40 apresenta baixa toxicidade, que se traduz como uma vantagem mercadológica e ambiental (Ecolife ${ }^{40}$, 199-?).

A amônia quaternária é recomendada para desinfestação de utensílios usados na colheita dos citros (Citrus spp.), roupas e sapatos de operários da citricultura, para erradicação da bactéria Xanthomonas axonopodis Vanterin et al., agente causal do cancro cítrico (Rossetti et al., 1980). Também pode representar uma opção no tratamento dos frutos de banana provenientes de áreas infestadas.

\section{REFERÊNCIAS BIBLIOGRÁFICAS}

AGROFIT. Site Ministério da Agricultura e Pecuária. URL:http:/ www.agricultura.gov.br/ Consultado em 4 de outubro de 2002

CALVO, C. \& ROMERO, R. Evaluación del gradiente de dispersión de la enfermedad de la sigatoka-negra del banano (Musa AAA). Corbana 23:51-56. 1998.

CORDEIRO, Z.J.M. \& MATOS, A.P. Doenças fúngicas e bacterianas. In: Cordeiro, Z.J.M. (Ed.) Banana Fitossanidade. Brasília. Embrapa/SPI. 2000. pp.36-65.
ECOLIFE ${ }^{40}$ :revigorante e anti-stress para plantas. São José dos Campos:uinabra, [199-?]. (Boletim Técnico).

GASPAROTTO, L., PEREIRA, J.C.R. \& TRINDADE, D.R. Situação atual da sigatoka- negra da bananeira. Fitopatologia Brasileira 26:448. 2001.

GASPAROTTO, L., PEREIRA, J.C.R., COSTA, M.M. \& PEREIRA, M.C.N. Fungicidas para o controle da sigatoka-negra da bananeira. In: Gato, A.M.G. \& Ronchi-Teles, B. (Eds.) Coletânea dos trabalhos da CDSV/AM. Manaus. MAPA, Delegacia Federal de Agricultura no Amazonas. 2002. pp.58-65.

GASPAROTTO, L. \& PEREIRA, J.C.R. Ecolife no controle da sigatoka-negra da bananeira. In: Gato, A.M.G. \& Ronchi-Teles, B. (Eds.) Coletânea dos trabalhos da CDSV/AM. Manaus:Delegacia Federal de Agricultura no Amazonas. 2002. pp.66-69.

HANADA, R.E., GASPAROTTO, L. \& PEREIRA, J.C.R. Esporulação de Mycosphaerella fijiensis em diferentes meios de cultura. Fitopatologia Brasileira 27:170-173. 2002b.

HANADA, R.E., GASPAROTTO, L. \& PEREIRA, J.C.R. Sobrevivência de conídios de Mycosphaerella fijiensis em diferentes materiais. Fitopatologia Brasileira 27:408-411. 2002a.

LICHTEMBERG, L.A. Pós-colheita de banana. In: Simpósio Norte Mineiro sobre a Cultura de Banana, 1, Nova Porteirinha, MG, 2001. Montes Claros: Unimontes, 2001. pp.105-130.

PEREIRA, J.C.R., GASPAROTO, L., COELHO, A.F.S. \& VÉRAS, S.M. Doenças da bananeira no Estado do Amazonas. Manaus: Embrapa Amazônia Ocidental Circular técnica no 7. 2000.

PEREIRA, J.C.R., GASPAROTTO, L., COELHO, A.F.S. \& URBEN, A.F. Ocorrência da sigatoka-negra no Brasil. Fitopatologia Brasileira 23:295. 1998. (Resumo)

ROSSETTI, V., VECHIATO, M.H. \& CARVALHO, M.L.V. Desinfectantes para cancro cítrico. In: Instituto Biológico. Pesquisas em citrus. São Paulo: Instituto Biológico, 1980. pp.10-11. 